\title{
A survey on Mitigation Techniques to Avoid the Problems Faced by Small Scale and Medium Scale Industries in India especially Sivakasi
}

\author{
K. Joiada Sheloni Rachee \\ Panimalar Institute of \\ Technology \\ Chennai, India
}

\author{
T. Blessline Ponmani \\ Panimalar Engineering College \\ Chennai, India \\ Lieutenant. J. Ganesan \\ Sree Sowdambika College of \\ Engineering, Aruppukottai, \\ India
}

\author{
D. Edison Selvaraj \\ Panimalar Engineering College \\ Chennai, India
}

\begin{abstract}
This paper deals with the problems faced by small scale industries in Sivakasi and some mitigation techniques to avoid the problems in the small scale industries in India. This paper also suggests some technological changes made in the industrial development in Sivakasi. Recent developments in the industries in Sivakasi were also discussed. Sivakasi was famous for many ancient mysterious temples and monuments. Sivakasi was also called as Odai Maa Nagar at ancient times. A big river crossed near the ancient Sivan temple in Sivakasi. That river was called as Odai River or Kiruthumal Odai. Many temples were located on the banks of River Odai in Sivakasi. That river was mainly encroached by many people of Sivakasi at the olden days itself. That river was one of the main branches of River Arjuna and Vaippar. This river made Sivakasi a prosperous one in the ancient time. But, now the river was encroached and destroyed by the people of Sivakasi. So, there was a dramatic water scarcity in Sivakasi. Hence, the people of Sivakasi should save the oldest river.
\end{abstract}

Keywords: Pyro industries; Nano technology; style; styling; insert (Minimum 5 to 8 key words)

\section{INTRODUCTION}

In Recent days, there was a decrease in the industrial development in the small and medium scale industries in India especially in Sivakasi. The reasons are many.But in this paper a small number of reasons responsible for the reduction in the development of small scale industries are given .At the mean time, some of the mitigation techniques to avoid the problems and failures in the small and medium scale industries were also discussed.

\section{DRAWBACKS OF INDUSTRIES IN}

\section{SIVAKASI}

- Low capital cost.

- Low income to workers.

- Poor infrastructure in industries and city.

- Not giving importance to the industries, instead spending much money in the unwanted expenditures.

- $\quad$ Poor maintenance.

- Not willing to work sincerely and honestly for the industries.

Enormous amount of self-minded and selfish people are increased in the recent years. Broad minded people are very less in the recent years.

Government is not supporting the small and medium scale industries in any part of the country except the big metro cities.
Illegal entry of license crackers.

Government is not bothered about the poor people. Instead they are also spending the money in unwanted expenditures.

- Government has to develop good roads, train facilities to all the parts of different states in India for the development of small villages, towns and tier II cities such as Madurai, Coimbatore, Erode, Thrichy, Nellai and Salem, Sivakasi, Tiruppur.

- $\quad$ There is no provision for the extension of small scale industries in the government budget.

- State government has also bother about the developments in all the parts of the state. Recently, the bus building industries in Karur has also struggling a lot due to the policies followed by state $\&$ central government.

Agriculture, agro based small scale industries, medium scale industries are the back bone of India. If the government is not bothering about the development of the small scale industries, then the country has to face a big economic crisis in the coming future because small drops make an ocean. Otherwise, India has to face many poverty related problems, unemployment related problems, poor sanitation and infrastructure related problems in the small towns \& cities if the government policies are against the development of small scale industries. 
Government has to motivate small and medium scale industries.

For the development of south Tamilnadu, Madurai international airport has to function properly; Government has to develop the infrastructure facilities in Madurai airport, Sivakasi bus stand, Sivakasi railway station, Madurai railway station, Madurai bus stand, Tirunelveli bus stand, Tuticorin airport, Tuticorin sea port, Tuticorin railway station.

They have to develop the infrastructure facilities in all parts of Tamilnadu. They have to develop agrobased industries in all the parts of India [10]. They have to eliminate unemployment \& poverty related problems in all the parts of the country.

People have to be well trained about the importance of the employment, infrastructure, industrial growth, sustainable development, environmental pollution, global warming \&climatic changes. Technology has to be changed as per the recent trends without destroying the conventional technology.

Only advances should be made without changing or replacing the conventional technology. All the development of the country is in the hands of the country development policies framed by the Indian government. So the government has to take much more effort to develop its citizens.

- The policy should satisfy at least the maximum number of people. In India, maximum numbers of peoples are middle class people. So, the government policies should give benefits to small scale \& medium scale industries present in the country. Industrial development of small and medium scale industries present in the countries. The development of the country is not in the development of metro cities; instead it is present in the development of small villages, towns present in the various parts of the country.

- Government has to encourage small and medium entrepreneurs present all over the country. In the coming future, the government policies will support the small and medium scale industries present in all the parts of India. It is the dream of all the citizens present in India.

Indians are always Indians. Indians will support only Indian products. Indian home made products should rule this world. Indians has to develop the quality standard in this world. The word Indian means quality.

- For that extreme, the Indians have to work hard as well as smart to develop our country. Always be Indian. Always support Indian products. India has to provide job opportunities to the foreign countries. Foreign peoples have to come and study in India.

- $\quad$ They have to create some innovative ideas for the development of India. Indian people have to train others about the medicine, agriculture, industrial growth, infrastructure facilities. Indian cities should rank first in the infrastructure facilities.

- India has to become a supernatural power in the coming days. For that, Indians has to support Indian products. For that, small and medium scale industries have to be supported and developed by all the Indians.

- India has to become a developed country in the coming future. That is present in all the hands of Indians. India will definitely become a developed country soon. This was the dream made by late Dr.A.P.J.Abdul kalam. His aim is develop India. Indian development is in the hands of small and medium scale industries. Indian development is in the hands of agriculture \& agro based industries. India has to develop in the irrigation facilities, infrastructure facilities, and sanitary facilities. India will change into a well-developed country in the coming future. For that all the Indians has to work hard. Indians has to work sincerely for the development of the nation. Good attitude among the people will develop the country. Good attitude can change a person. A good person has the power to change his family. A good family has the ability to change the capability to change the town. A good town can change the district. A better district can change the state best.

- The best state can change the whole country. The whole country can change this world brighter and brighter. So, all the people have to be positive towards their work. They have to acquire more positive ideas, thoughts, knowledge for the development of the country and the world.

\section{RECENT DEVELOPMENTS IN THE INDUSTRIES IN SIVAKASI}

\section{1. $\quad 3 \mathrm{D}$ printing}

Rapid prototyping and additive manufacturing methods are available in industries located in Sivakasi [2]. 3D printing is very much popular in Sivakasi. These machines are imported from foreign countries. Traditional machines are replaced by modern machines in the industries located in Sivakasi. Sivakasi is an industrial hub having many modern printing, scoring, calendar works, candle works, match works and Pyro works [8]. The main drawback is the export of the products to foreign countries by Cargo and flights. The officers are not at all bothering about the products made in Sivakasi. The officers are not at all bothering about the products made in Sivakasi. The officials are not giving the clearances for the products made in Sivakasi. If the clearance work process is very easy, then many products can be exported to many industrial downs located in many parts of the world. So, Government has to make the clearance process an easy one. Then, definitely Sivakasi will become $100 \%$ benefited industrial city. It will become a mega industrial hub in the world. It will attract many foreign investments in the coming future. Government has to take necessary steps.

- To develop the industries located in Sivakasi

- To make the cargo process an easy one

- To develop the infra structure in Sivakasi

- To develop Tuticorin Airport and Seaport

- To develop Madurai International Airport 
To rush up and finish Shencottai to Punalur broad gauge work.

It will make connectivity between Sivakasi and Kochi Seaport and Airport. It will make connectivity between Sivakasi and Trivandrum International Airport. The delay in the broad gauge conversion between Shencottai and Punalur was also one of the drawbacks of reduction in industrial development in Sivakasi. Previously, during the last decades Sivakasi has the railway line between Alankulam cement factories. At that time, Sivakasi was one of the main junctions in the virudhunagar district. Many trains crossed between Sivakasi and Kerala. The gauge conversion work was very slow in these days. So, Government has to rush up the gauge conversion work and finish as soon as possible. The delay in the gauge conversion work brought a drastic reduction in the industrial development in Sivakasi. Before 20 years, many Kerala workers and traders will come to Sivakasi for their trade and work. Now, the people located near Kollam, Trivandrum and Cochin is not at all visiting Sivakasi because of the delay in the gauge conversion work. Government has to finish the gauge conversion work as soon as possible. To rush up and finish the Palakkad to Punalur broad gauge work. This path will connect Sivakasi with Mumbai and major parts of Gujarat. So the delay in the gauge conversion work in Coimbatore district is also one of the major Drawbacks of reduction industrial growth in Sivakasi, Madurai and Coimbatore. British Government has made good railway transport in Tamilnadu by connecting all the districts in Tamilnadu, connecting Tamilnadu with Kerala, Karnataka and Andra Pradesh. But, Indian Government did not give importance to Tamilnadu in the railway department. The olden paths were replaced into broad gauge in a slow manner. Government has to take necessary steps to finish all the gauge conversion work in Tamilnadu as soon as possible. Tamilnadu has to be connected with nearby states at all the possible ways of communication land ways (railways and road ways), Airways and water ways. Tamilnadu should be developed in both agriculture and industries. Many small scale industries are the back bone of Tamilnadu. Both, Indian Government are not giving preference in the development of all districts of Tamilnadu in the last decades. Maximum fund can be spend for the infrastructure development of all districts of Tamilnadu especially the southern districts of Tamilnadu. Southern districts of Tamilnadu are responsible for the tremendous growth of Tamilnadu in the previous countries. But, under 20 years only, there is no recent development in Tamilnadu. After 2000, there is no tremendous development in the southern districts of Tamilnadu. Sate and central Government did not spend their interest to develop the southern districts of Tamilnadu. There was a tremendous migration of people from southern districts to Chennai, Covai, Tiruppur, Salem, Erode, Bangalore, Mumbai, Hyderabad and Delhi. Government has to take efforts to develop the Southern districts of Tamilnadu especially Virudhunagar, Madurai, Theni, Tirunelveli, Tuticorin, Trichy, Dindigul and
Sivagangai districts. These districts are responsible for the development of small scale industries in Tamilnadu.

2. Nano pyro industries [1]

3. Solar industries [7]

4. Transformer manufacturing units

5. Chemical industries [5]

6. Powder metallurgy [6] - Ball mill, sintering

7. Candle works

8. Nano printers [4]

- Calendars

- Articles

- Journals

- Papers

- Presentation works

-3D plastic models

- Arts, scientific models

9. Introducing the advances in the existing science \& technology in the city.

10. Improving the communication facility to the city.

$\begin{array}{ll}\text { - } & \text { Roads } \\ \text { - } & \text { Airways } \\ \text { - Water ways } \\ \text { 1. Inland } \\ \text { 2. Seaways } \\ \text { IT developments } \\ \text { Postal developments } \\ \text { - } \quad \text { Land lines } \\ \text { - } \text { Advances in mobile } \\ \text { Communication-service centers, show } \\ \text { rooms, improving the quality of signals } \\ \text { using nano technology in communication } \\ \text { lines. } \\ \text { Encouraging power line communication s. } \\ \text { Internet cables, fiber optic cables, satellite } \\ \text { communication. }\end{array}$

\section{ENCOURAGING ROAD FACILITIES IN THE CITY}

1. Construction of new over bridges in the railways, main road junctions.

2. Construction of new subways in the railways, main road junctions.

3. Extension of available road facilities in the city.

4. Extending the width of the roads in the city.

5. Constructing new pass over for the pedestrians 
7. Construction of new bus stands for mofussil buses, Omni buses, town buses, mini buses.

8. Construction of lorry stands, van stands and load cabs stand, auto stand.

9. Periodic maintenance and proper system maintenance and proper monitoring of the system are needed for the technical developments in the city.

10. Promoting agriculture in the city.

- Introducing new revolutions in the agriculture.

- Development of agricultural lands, irrigation facilities in the city.

- Avoiding the usage of unwanted chemicals for pesticides, fertilizers.

- Usage of environment and nature based fertilizers, pesticides.

- Creating a sustainable development in the city.

- Using nano green technology in the industries and avoiding pollution in the city.

\section{ACHIEVEMENTS IN SIVAKASI}

- To develop a new golden city in Sivakasi as per God's instructions. Solar industries were functioning in Sivakasi to make the city more powerful and beautiful. Green electricity was the electricity which does not harm the environment.

- $\quad$ Creating great infrastructures in Sivakasi.

- Developing wealth in Sivakasi.

- Developing lands in Sivakasi.

- Developing all the human resources available in Sivakasi.

Developing roads, train facilities, airport and sea port facilities to the city Sivakasi.

It would be 13th city in Tamilnadu with great infrastructures and all the available facilities.

To create new industrial revolution in Sivakasi by encouraging existing industries, replacing the olden technology, creating advances in the conventional technology, introducing some advanced technology without affecting the human resources in Sivakasi [3].

- Constructing new roads in and around Sivakasi.

- $\quad$ New railway bridges.

- Roads along the streams.

Extension of small bridges in many main roads in our Sivakasi would be effective for better development of the city. It will create great roads and great look for our Sivakasi. Extension roads on the encroached areas and streams in the main areas will reduce traffic in our Sivakasi... A small road should be constructed from RC church to KTR Bridge to reduce traffic and to connect main areas in Sivakasi. Likewise many small roads should be constructed in Sivakasi to reduce traffic and to improve the infrastructure in our Sivakasi.

Sivilliputhur - Sivakasi - Virudhunagar Tiruchuzhi - Parthipanoor (105 km) state highway was upgraded to National Highways.

- Replacing encroachments by good road.

- Outer ring road and Inner ring road.

- $\quad$ Bye pass road.

- $\quad$ Extending the existing roads.

- To develop water facilities in Sivakasi.

- Promoting the existing lakes, ponds, rivers in Sivakasi.

- $\quad$ Creating new water bodies in Sivakasi.

- Developing the train facilities in Sivakasi by constructing new railway lines near to Sivakasi.

- $\quad$ Promoting railway station

- Interconnecting nearby railway stations by new railway routes.

\section{STOP CHINESE CRACKERS}

Chinese crackers use potassium chloride as explosive element which is highly unsafe and toxic to the environment. It will damage the environment and the liver of the human being where as Sivakasi crackers use potassium nitrate as the primary element for the crackers. Sivakasi crackers were from 1920 onwards following the rules and regulations given by the International Standards and Government of the various countries. Sivakasi crackers are highly safe and cause artificial rain in the driest areas. Sivakasi crackers can be handled easily. It will produce fine quality of sound in the celebrations. It won't affect the environment as the Chinese crackers can do. Sivakasi crackers are marching towards its perfection and reaching 100th anniversary in 2020. But in the recent days, from 2013 to 2015, Chinese crackers are affecting the market value of Sivakasi crackers. Chinese crackers are sold at low cost. Chinese crackers are entering into the market in the disguise of toys and other machineries in India. Recently, Central Government has banned the entry of Chinese crackers. But, they are entering into the Indian market illegally. The workers of Sivakasi were seriously opposing the entry of Chinese crackers. Recently there was a great revolt against the illegal entry of Chinese crackers. People won't encourage the illegal entry of Chinese crackers in the coming future because people don't want low cost crackers instead they need Indian and safe Sivakasi crackers. So the illegal entry of Chinese crackers will be stopped in the coming months [9]. The crackers of Sivakasi town will face the uphill in the coming future. Hereafter, there won't be the illegal entry of Chinese crackers. But, Government won't recommend the entry of Chinese crackers directly and indirectly. In the coming future the world market value of Sivakasi crackers will increase by two to four times when compared to the past peak values. Government will get maximum revenue from Sivakasi crackers. The people and workers are paying sales tax, revenue tax and income tax to Government, thereby encouraging the revenue of the state and central Government. Sivakasi is the only town which pays 100 $\%$ tax to both state and central Government. So, people will encourage only the Sivakasi crackers. The Government of India and people of Sivakasi have planned to destroy the unsafe and illegal Chinese crackers. People won't recommend 
the unsafe, illegal, highly explosive and low cost Chinese crackers [10]. The prime minister of India will encourage the Indian Products. People of Sivakasi are having the faith on Government because the officials and authorities will ban the illegal entry of Chinese crackers. Recently, 500 containers of Chinese crackers were seized by the central Government in Mumbai, Gujarat and Tamilnadu sea ports. The illegal chine crackers will face the downhill when people also help to save Sivakasi crackers. People will have a Happy Diwali with everlasting and unbeatable glory Sivakasi Crackers.

\section{CONCLUSION}

This paper will make hope for the development of small\& medium scale industries in Sivakasi. This paper will help the people to develop their faith and hope towards the development of industries in Sivakasi.This paper will definitely make an industrial revolution in India . This paper especially will create at tremendous changes in the infrastructure of the industrial city Sivakasi .This paper will make the government Authorities to improve the small scale industries in Sivakasi by avoiding illegal business transactions .Chinese crackers are entering the country illegally. This paper will avoid the legal entry of Chinese crackers to India Chinese crackers should not enter illegally in India .This will make unemployment in industries in India .This paper will make the nation great. This paper will help the people to develop the industries in India. This paper will make an industrial revolution in India. An Industrial revolution is going to happen in small scale industries in India soon. This industrial development will happen within this year itself.

\section{REFERENCES}

[1] Edison selvaraj. D, et.al Applications of Nano Technology in Pyro Industries located in Sivakasi, International Journal of Science and Engineering Applications Volume 4 Issue 4, 2015.

[2] Edison Selvaraj. D, et.al "Estimation of Losses on $3 \Phi$ Nano Coated Induction Motor" Applied Mechanics and Materials Vol.666 (2014) pp. 213-217 (2014) Trans Tech Publications, Switzerland.

[3] Edison Selvaraj. D, Pugazhendhi Sugumaran. C, Lieutenant Ganesan. J, Ramathilagam. J, "Analysis of Dielectric and Thermal Properties of Polyamide Enamel Filled with Carbon Nano tubes" International Journal of Nano science, Vol.12, Issue 3, June 2013.

[4] Edison Selvaraj, D., C. Pugazhendhi Sugumaran, and A. Sivaprakash "Characterization of Electrical and Thermal Properties of Enamel Filled with Carbon Nanotubes", Proceedings of the Third International Conference on Trends in Information, Telecommunication and Computing, Springer New York, 2013.

[5] Selvaraj, D. E., Priyan, S. S., Joshi, M. R., Sugumaran, C. P., Kannan, R., Raj, R. A., Kumar, B. M., Prakash, R., Ganesan, J., Krishnamoorthi, D., \& Kumar M. R, "A Review on The Nano Fillers Used for Electrical Apparatuses", Journal Club for Electrical Engineering (JCEE), Vol.1, Issue 1, pp 8 -17, Aug 2014.

[6] Selvaraj, E. D., Priyan, S. S., Joshi, M. R., Sugumaran, C. P., Kumar, B. A., Kumar, M. A., Kumar, S. A., Khan, A. H., Kannan, R., Ganesan, J., Kumar, R., Kumar S. D, "A Review on the Fabrication Methods Used in Nano Technology for The Fabrication of Nano Fillers Used in Electrical Apparatuses", Journal Club for Electrical Engineering (JCEE), Vol.1, Issue 1, pp , Aug 2014.
[7] Joshi MR Selvaraj DE, Kumar GS, Mohan BR, Sugumaran CP, Kumar RM, Ganesan J, "A Lecture Notes for Understanding the Fundamentals of Fabrication of Nano Fillers", Journal Club for Electrical Engineering (JCEE), Vol.1, Issue 2, pp 1 -16, Oct 2014.

[8] www.sivakasionline.com

[9] www.kuttyjapan.com

[10] www.sivakasiweeklyonline.com 